\title{
Use of alloy 59 for the transport of highly corrosive dangerous goods
}

\author{
Margit Weltschev ${ }^{1,}$, , Ralph Baessler ${ }^{2, b}$ \\ ${ }^{1,2}$ BAM-Federal Institute for Materials Research and Testing, D-12200 Berlin, Germany

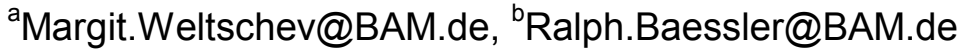

Key words: Nickel alloy, transport tanks of dangerous goods, proof of compatibility

\begin{abstract}
Alloy 59 (NiCr23Mo16Al) with a lot of chromium, molybdenum and nickel possesses excellent resistance not only to reducing but also oxidizing chemicals.

Both the Nickel alloy 59 and the superaustenitic steel alloy 31 have already been used as shell materials for tank vehicles or tank containers. Use of these alloys allows the transport of a significantly wider variety of chemicals and, especially, waste mixtures than the use of common austenitic steels. Another advantage is the extension of test interval for transport tanks.

In Germany the "BAM-List - Requirements for Tanks for the Transport of Dangerous Goods" is the basis for substance-related prototype approvals for tank containers designed for the carriage of dangerous goods issued by the Federal Institute for Materials Research and Testing (BAM). Compatibility evaluations of selected metallic material groups as well as polymeric gasket and lining materials under the influence of approximately 7000 dangerous goods and water-polluting substances are published in the BAM-List. Alloy 59 belongs to the group of metallic materials in the BAMList.

Due to the large number of dangerous goods in the BAM-List BAM, IKS Dresden and ThyssenKrupp VDM performed a comprehensive corrosion test programme with welded specimens of the nickel alloy 59 and the superaustenitic steels alloy 926 and alloy 31 in the period $2002-2010$. In particular alloy 59 and alloy 31 were exposed to a large number of corrosive substances such as various mixtures of both nitric acid/sulphuric acid and nitric acid/phosphoric acid at $55{ }^{\circ} \mathrm{C}$. Other corrosive test substances were different organic and inorganic halogenides, peroxyacetic acid and molten substances. In the case of molten chemicals such as monochloroacetic acid the test temperature was increased to more than $100^{\circ} \mathrm{C}$. The test results presented in this paper are already included in the $10^{\text {th }}$ edition of the BAM-List and, therefore, available to the customer.
\end{abstract}

\section{Introduction}

Compatibility evaluations of conventional metallic materials (i.e. carbon, austenitic $\mathrm{CrNi}$-, $\mathrm{CrNi}$ Mo-steels and aluminium) for tank containers and transport tanks are available in the "BAM-List Requirements for Tanks for the Transport of Dangerous Goods" [1]. Such information about corrosion resistance is applicable for tank trucks and rail cars too.

Unless otherwise specified, the compatibility evaluations apply for average operating temperatures up to $50{ }^{\circ} \mathrm{C}$. They do not only contain the evaluation of corrosion caused by the dangerous good on the material but also potential dangerous effects of the material on the medium to be transported.

According to the international dangerous goods regulations ADR/RID for road and rail transport in Europe and the IMDG-Code for international maritime carriage a compulsory internal inspection of the tank is required after a certain period. The test interval is generally five years for tank containers and six years for road tank vehicles. For rail tank cars test intervals of four and eight years are required by the dangerous goods regulations. For the time of the test intervals the corrosion resistance of the tank material must be provided considering the following criteria. 
Material/substance combinations for test intervals of 5, 6 and 8 years are considered suitable if

- wall thickness reduction due to uniform corrosion does not exceed $0.1 \mathrm{~mm} / \mathrm{year}$ and

Material/substance combinations for test intervals of $2 \frac{1}{2}, 3$ and 4 years are considered suitable if

- wall thickness reduction due to uniform corrosion does not exceed $0.5 \mathrm{~mm} / \mathrm{year}$

Localized corrosion effects in the form of pitting corrosion, stress corrosion cracking and crevice corrosion have to be excluded.

Corrosive substances, which require materials with a higher corrosion resistance than listed in the BAM-List, are halogen containing media and oxidizing or reducing acids. The corrosion risk while carrying these substances needs to be considered to be very high due to often performed change of transport medium, because after the cleaning process some moisture remains inside the tank. Furthermore costs rise due to additional internal inspections of tanks. One possible way to solve this problem is coating or lining the tanks by a polymeric material. An alternative is the application of high-alloyed steels and nickel alloys for transport tanks.

The nickel alloy 59 (NiCr23Mo16Al, 2.4605) as well as the "super austenite" alloy 31 (X1NiCrMoCu32-28-7, 1.4562) are a good alternative to coated or lined tanks for transport of corrosive chemicals and waste due to its good resistance against pitting and crevice corrosion. Due to the higher strength of the material the tank wall thicknesses can be reduced considering the requirements of the international regulations for transport of dangerous goods. This allows a reduction of the tank weight. Therefore these materials were chosen to be added to the BAM-List.

\section{Experimental setup}

Test substances The exposure was carried out according to DIN 50905/4. The test results of one material determined the following corrosion tests either with the lower or higher-alloyed material. The tests were performed in representatives of the following highly corrosive substance groups: 1. Inorganic halogenides (ferric chloride),

2. Halogenic carbonic acids (2-chloropropionic acid),

3. Chlorates and chlorites (barium chlorate, sodium chlorite and sodium hypochlorite),

4. Hydrogen sulphates (potassium hydrogen sulphate)

5. Inorganic acids (perchloric acid, hydrochloric acid)

6. Mixed acids (mixture of nitric and sulphuric acid)

Setup Each set of test specimens was fixed in a sealed 31 glass receptacle by non-extruding PTFEthreads completely dipped into the solution, in the intermediate phase and in the vapour phase in a temperature controlled box at $55 \pm 1{ }^{\circ} \mathrm{C}$ (see Fig. 1). The distance between the upper edge of the completely inserted specimen and the surface of the liquid was supposed to be at least $10 \mathrm{~mm}$.

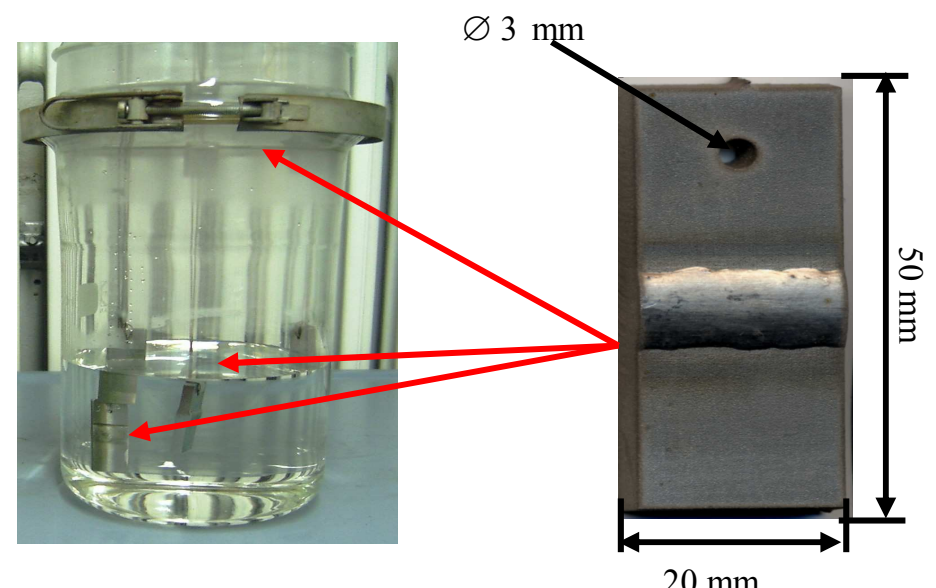

Figure 1: Specimen and exposure location 
Preparation Specimens, water jet cut and equipped with a hole, having dimensions of $50 \mathrm{~mm} \mathrm{x}$ $20 \mathrm{~mm} \times 5 \mathrm{~mm}$ with centered located, $20 \mathrm{~mm}$ long weld made of FM 59) were deburred by grinding paper, cleaned by brushes under flowing water, degreased by ultrasound and acetone, flushed with water / distilled water / ethanol and dried with warm air.

Mass loss was determined by weighing before and after exposure. After removal from the medium specimens were flushed with water, brushed, flushed with water and acetone and dried with warm air. Specimens were evaluated by optical microscopy. Especially signs of localized corrosion were of interest. After one week the specimens were examined for the first time, following that after two and four weeks. Maximum values were used for the characterization of the corrosion resistance.

It was distinguished between pitting and shallow pit corrosion in order to use the right criteria for suitability evaluation.

\section{Results}

Ferric chloride Alloy 59 can be considered resistant in the whole concentration range. Even in the saturated solution the corrosion rate is below $0.005 \mathrm{~mm} /$ year.

The steel alloy 31 corrodes in the saturated ferric chloride solutions $55^{\circ} \mathrm{C}$ and is resistant in $25 \%$ and in lower concentrated ferric chloride solutions with a corrosion rate $<0.01 \mathrm{~mm} /$ year (Figure 2). The very high corrosion rates occurring during activation can be explained by the high content of oxidizing components in the solution.

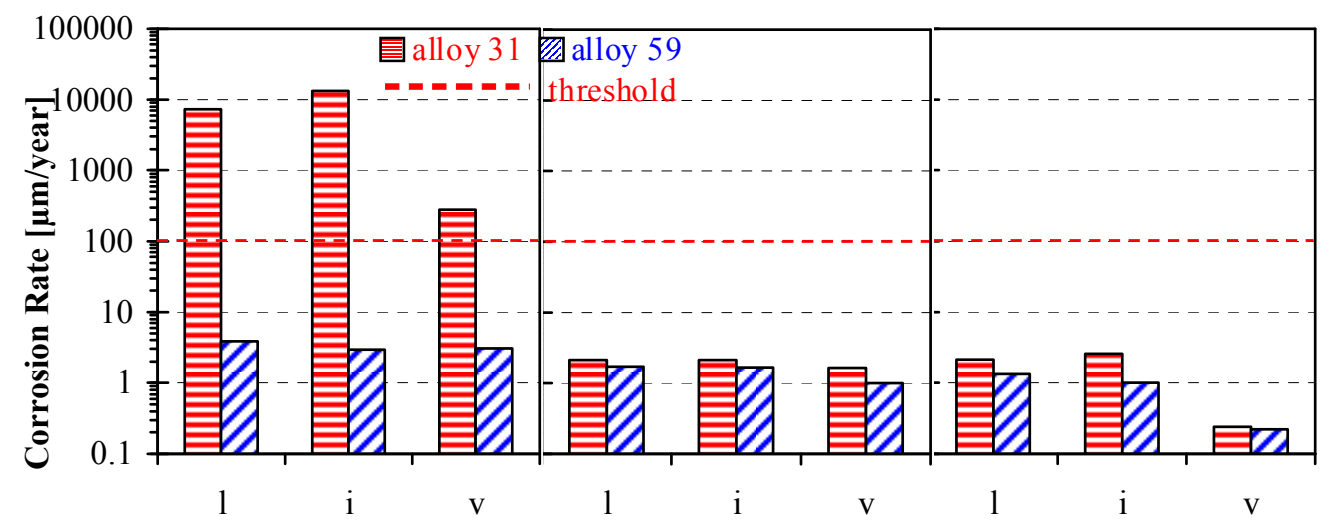

Figure 2: Corrosion rates of alloy 59 and alloy 31 in saturated (left), $5 \%$ (centre) and $0.1 \%$ (right) ferric chloride solutions at $55^{\circ} \mathrm{C}$ (liquid (1), intermediate (i) and vapour (v) phases)

2-Chloropropionic acid Alloy 59 is resistant in this representative of halogen carbonic acids up to a acid concentration of $90^{\circ} \%$ (with $4-6 \%$ 2.2-Dichloropropionic acid) du to its corrosion rate of $<0.05 \mathrm{~mm} /$ year. However alloy 31 corrodes with $0.5 \mathrm{~mm} /$ year in the vapour phase (Fig. 3).

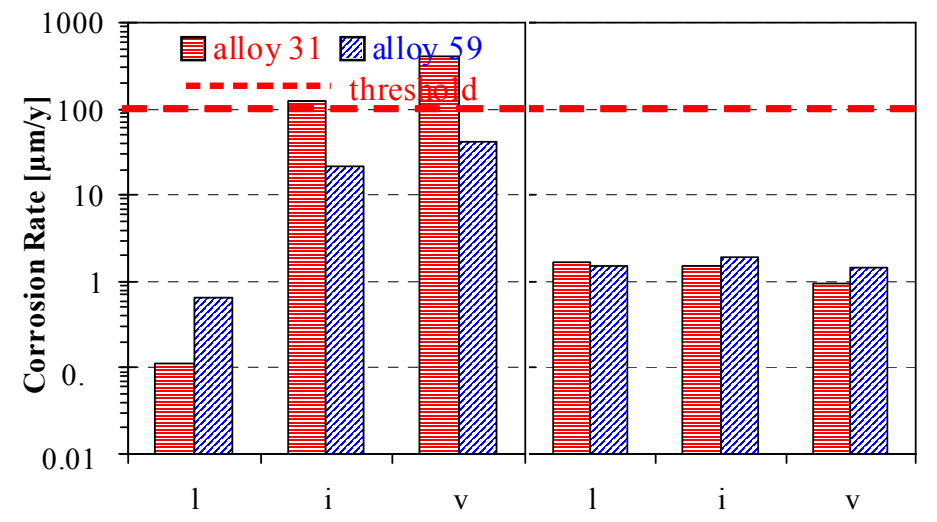

Figure 3: Corrosion rates of alloy 59 and alloy 31 in $90 \%$ (left) and $5 \%$ (right) in 2-chloropropionic acid at $55^{\circ} \mathrm{C}$ (1...liquid, i...intermediate, v...vapour phase) 
Barium chlorate For alloy 59 corrosion rates $<0.001 \mathrm{~mm} /$ year were determined in different barium chlorate solutions at $55^{\circ} \mathrm{C}$. Values for alloy 31 were below $0.002 \mathrm{~mm} /$ year (Fig. 4).

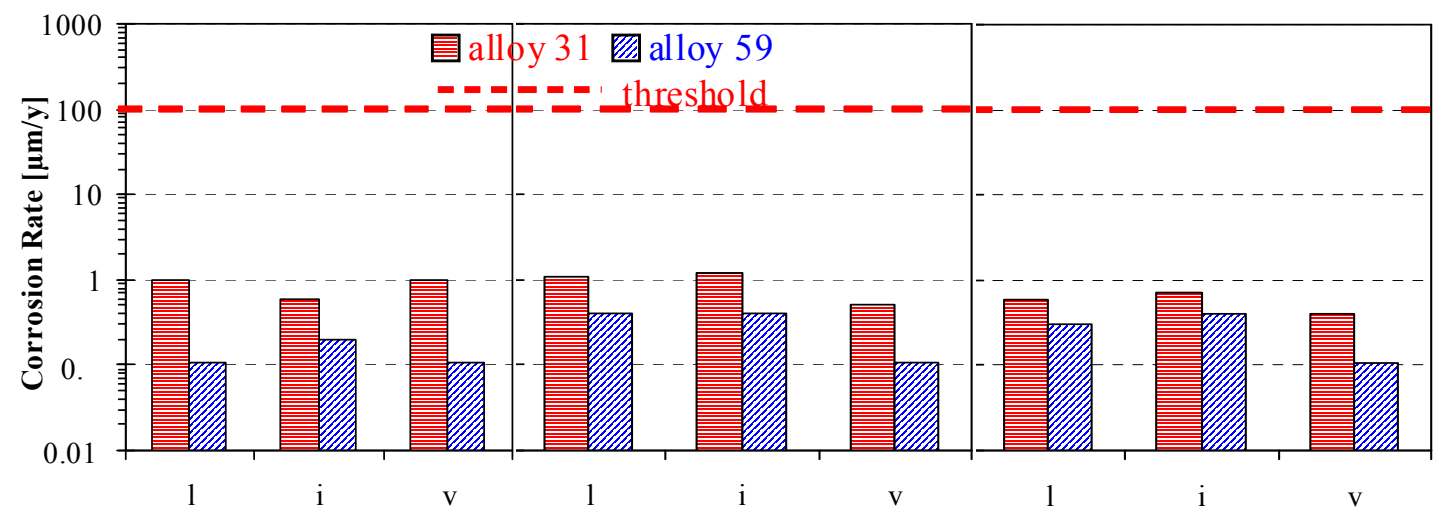

Figure 4: Corrosion rates of alloy 59 and alloy 31 in saturated (left), $5 \%$ (centre) and $0.1 \%$ (right) aqueous barium chlorate solution at $55^{\circ} \mathrm{C}$ (1...liquid, i...intermediate, v...vapour phase)

Sodium chlorite and sodium hypochlorite The nickel alloy and the super austenite alloy 31 show a very good corrosion resistance within the whole concentration range of sodium chlorite, having corrosion rates below $0.01 \mathrm{~mm} /$ year at $55^{\circ} \mathrm{C}$ (Fig. 5). Both alloys can be rated completely corrosion resistant in saturated and $0.1 \%$ sodium hypochlorite solution too.

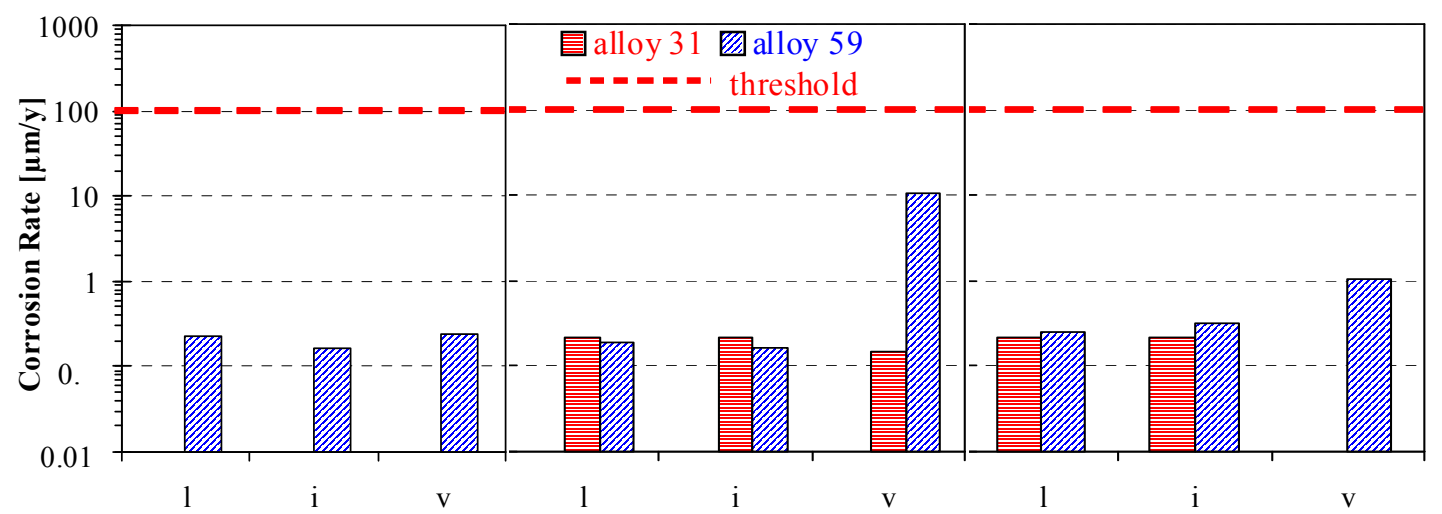

Figure 5: Corrosion rates of alloy 59 and alloy 31 in saturated (left), $5 \%$ (centre) and $0.1 \%$ (right) aqueous sodium chlorite solution at $55^{\circ} \mathrm{C}$; (1...liquid, i...intermediate, v...vapour phase)

Potassium hydrogen sulphate The diagram of measured corrosion rates shows values far below the threshold. It can be concluded that both alloy 59 and alloy 31 are resistant (Fig. 6).

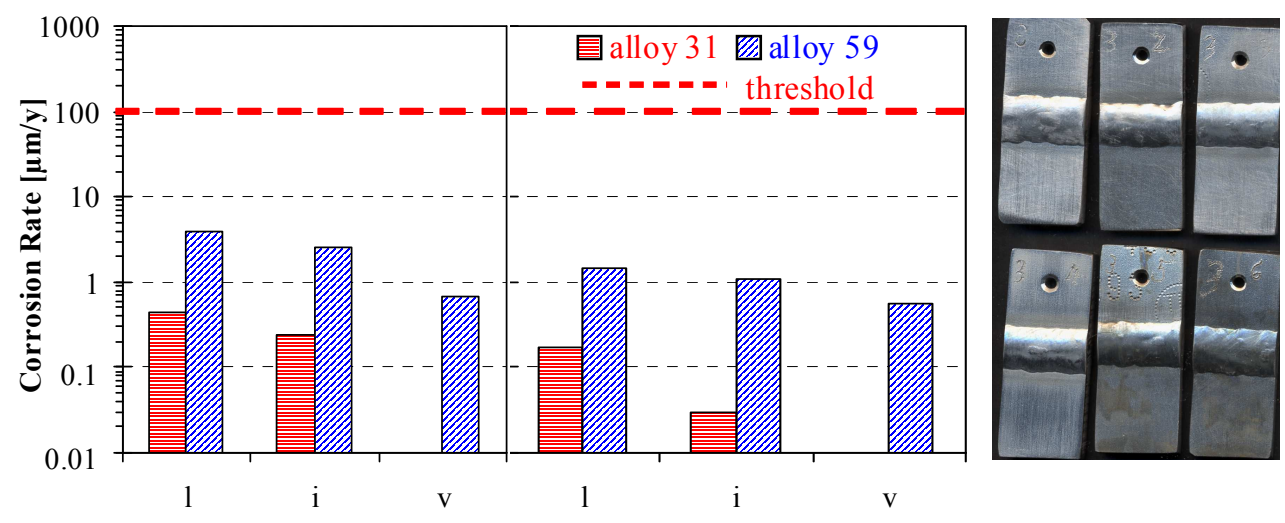

Figure 6: Corrosion rates of alloy 59 and alloy 31 in saturated (left) and $0.1 \%$ (right) aqueous potassium hydrogen sulphate solution at $55^{\circ} \mathrm{C}$; test specimens made of alloy 59 after exposure to saturated solution (1...liquid, i...intermediate, v...vapour phase) 
Perchloric acid Alloy 59 is resistant in the whole concentration range of perchloric acid. Alloy 31 is resistant in $0.1 \%$ solution only, otherwise a classic uniform corrosion can be observed, leaving the over-alloyed weld intact (Fig. 7).

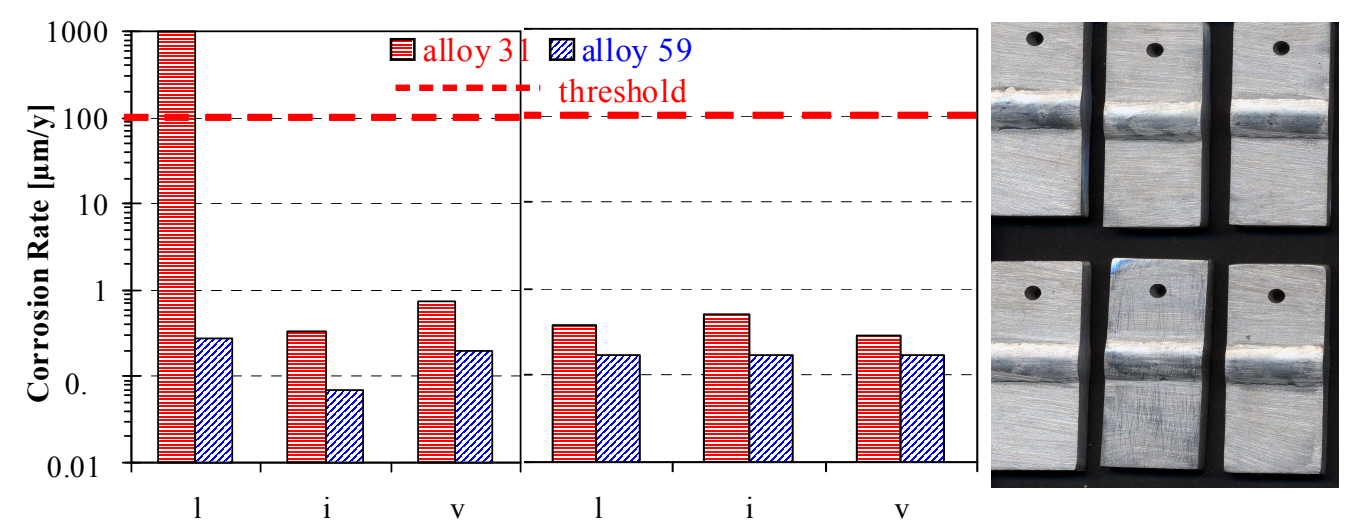

Figure 7: Corrosion rates of alloy 59 and alloy 31 in concentrated (left) and $0.1 \%$ (right) perchloric acid at $55^{\circ} \mathrm{C}$ (1...liquid, i...intermediate, v...vapour phase), specimens made of alloy 59 after exposure in concentrated perchloric acid at $55^{\circ} \mathrm{C}$

Hydrochloric acid There are only few materials suitable for this reducing behaving acid. Alloy 31 can only be applied to chemical processes where small amounts of hydrochloric acid are involved. The application of the nickel alloy 59 is limited to a temperature up to $40{ }^{\circ} \mathrm{C}$ (Fig. 8).

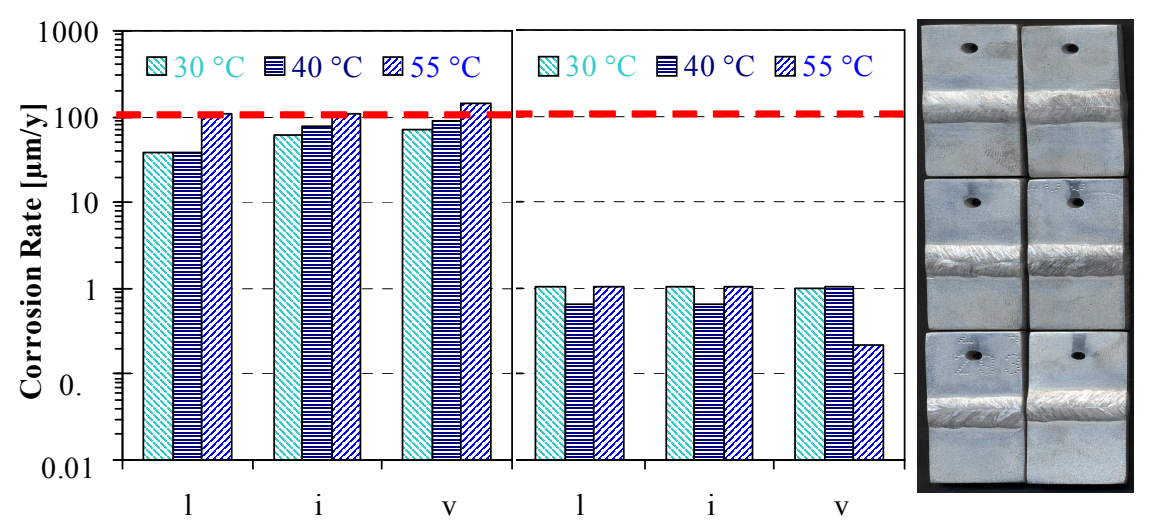

Figure 8: Corrosion rates of alloy 59 in concentrated and $0.1 \%$ hydrochloric acid at different temperatures (1...liquid, i...intermediate, v...vapour phase), specimens made of alloy 59 after exposure in concentrated hydrochloric acid at $40{ }^{\circ} \mathrm{C}$

Mixtures of nitric and sulphuric acid Alloy 59 shows clearly better corrosion resistance in the mixtures of nitric and sulphuric mixtures at $55^{\circ} \mathrm{C}$. A maximum corrosion rate of $0.024 \mathrm{~mm} / \mathrm{a}$ was determined in a mixed acid of $66 \%$ concentrated nitric acid and $34 \%$ of $96 \%$ sulphuric acid after an exposure time of two weeks. Lower corrosion rates in the liquid phase were measured if the content of the nitric acid is reduced to $33 \%$. The nickel-based alloy corrodes with increasing content of nitric acid in the vapour phase too, even though the corrosion rates are less than $0.1 \mathrm{~mm} / \mathrm{a}$ (see Fig. 9). 


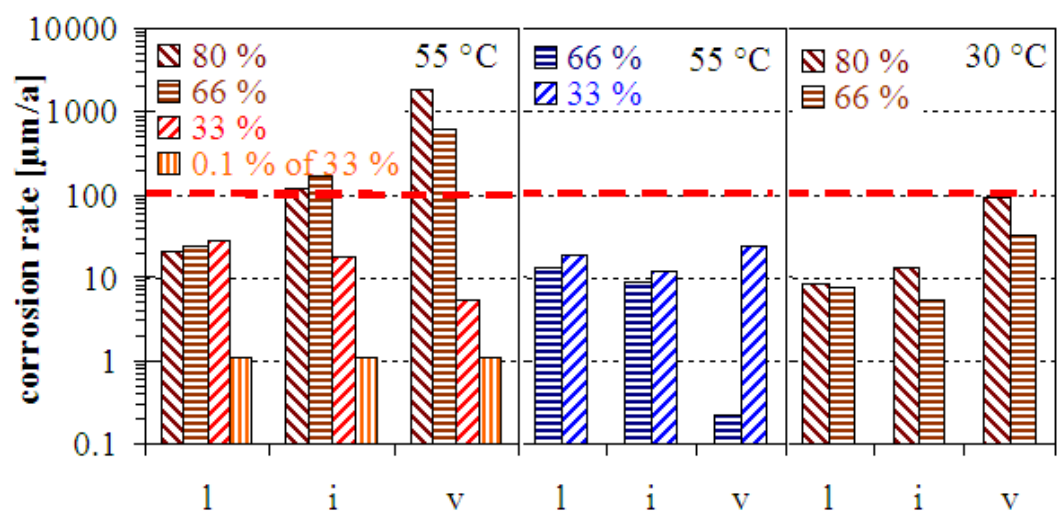

Figure 9: Corrosion rates (left: alloy 31 ), $55^{\circ} \mathrm{C}$, centre: alloy $59,55{ }^{\circ} \mathrm{C}$, right: alloy $31,30{ }^{\circ} \mathrm{C}$ after 4 weeks exposure in different $\mathrm{HNO}_{3} / \mathrm{H}_{2} \mathrm{SO}_{4}$-mixtures (always Vol. \%-value of content of $67 \% \mathrm{HNO}_{3}$, rest is $96 \% \mathrm{H}_{2} \mathrm{SO}_{4}$ )

\section{Summary}

As expected due to the different alloying components, especially chromium, nickel and molybdenum, differences of the corrosion behaviour of alloy 59 in comparison with alloy 31 were observed in the various substances. Alloy 59 is more corrosion resistant than alloy 31 . However both materials face localized corrosion in substances containing halogenides, which often can be prevented in limiting the transport temperature (i.e. use of insulated tanks).

Concluding, it can be stated, that both alloy 59 and alloy 31 are a good alternatives to the lining of tanks in order to carry corrosive dangerous goods. Intensive publication [2-7] of results achieved so far has led to production of new tank trucks and containers made of these alloys. The evaluation of the tested material/medium combination is incorporated in the $10^{\text {th }}$ issue of the BAM-List.

\section{References}

[1] BAM-List ,Requirements on Tanks for transport of dangerous goods“, $10^{\text {th }}$ edition, BAM, Section III.2, Berlin (2009)

[2] Bäßler, R.; Weltschev, M.; Werner, H.; Alves, H., Behrens, R.: Evaluation of the corrosion resistance of high-alloyed metallic materials for transport tanks of dangerous goods and waterpolluting substances. EUROCORR 2004 - The European Corrosion Congress, Nizza (2004)

[3] Weltschev, M., Bäßler, R.; Werner, H.; Alves, H. and Behrens, R.: Resistance Evaluation of High-Alloyed Materials for Use as Tank Materials for Transport of Dangerous Goods and Water Polluting Substances; Materials Week Munich (2004)

[4] Bäßler, R.; Weltschev, M.; Werner, H.; Alves, H.: More Corrosion Resistant High-Alloyed Metallic Tank Materials for Transport of Dangerous Goods and Water-Polluting Substances, Stainless Steel World, Houston USA (2004)

[5] Weltschev, M.; Bäßler, R.; Werner, H.; Alves, H.; Behrens, R.: Use of Corrosion resistant High-Alloyed Metallic Materials for Transport Tanks of Dangerous Goods and Water-Polluting Substances, EUROCORR 2005- The European Corrosion Congress, Lisboa, Portugal (2005)

[6] Weltschev, M.; Bäßler, R.; Werner, H.; Alves, H.; Behrens, R.: Use of Corrosion Resistant High-Alloyed Metallic Materials for Transport Tanks of Dangerous Goods, Stainless Steel World Conference, Maastricht, Netherlands (2005)

[7] Weltschev, M.; Bäßler, R.; Langer, M.; Alves, H.: Suitability of Alloy 31 and 59 for Transport of Highly Corrosive Dangerous Goods, NACE International Conference, Corrosion 2009, Atlanta, USA (2009) 